\title{
Awake craniotomy using a high-flow nasal cannula with oxygen reserve index monitoring - A report of two cases -
}

\section{Joonhee Gook', Ji-Hye Kwon' ${ }^{1}$, Jung Won Choi' ${ }^{2}$ Keoungah Kim³, Ik Soo Chung ${ }^{1}$, and Jeonjin Lee ${ }^{1}$}

1 Department of Anesthesiology and Pain Medicine, Samsung Medical Center, Sungkyunkwan University School of Medicine, Seoul, ${ }^{2}$ Department of Anesthesiology and Pain Medicine, Dankook University Dental Hospital, Cheonan, ${ }^{3}$ Department of Neurosurgery, Samsung Medical Center, Sungkyunkwan University School of Medicine, Seoul, Korea
Received March 9, 2021

Revised August 23, 2021

Accepted September 1, 2021

\section{Corresponding author}

Jeongjin Lee, M.D., Ph.D.

Department of Anesthesiology and

Pain Medicine, Samsung Medical

Center, Sungkyunkwan University

School of Medicine, 81 Irwon-ro,

Gangnam-gu, Seoul 06351, Korea

Tel.: 82-2-3410-2467

Fax: 82-2-3410-2467

E-mail: jjeong.lee@samsung.com

Joonhee Gook and Ji-Hye Kwon

contributed equally to this study.
Background: Awake craniotomy is a well-tolerated procedure for the resection of brain tumors residing within or close to the eloquent cortical areas. Monitored anesthesia care (MAC) is a dominant anesthetic approach for awake craniotomy; however, it is associated with inherent challenges such as desaturation and hypercapnia, which may lead to various complications. The prevention of respiratory insufficiency is important for successful awake craniotomy. As measures to avoid respiratory depression, the use of high-flow nasal cannula (HFNC) can improve patient oxygenation and monitor the monitoring the oxygen reserve index (ORi) can detect hypoxia earlier.

Case: We report two cases of awake craniotomy with MAC using HFNC and ORi. We adjusted the fraction of inspired oxygen of the HFNC according to the ORi level. The patient underwent successful awake craniotomy without a desaturation event or additional airway intervention.

Conclusions: Combined HFNC and ORi monitoring may provide adequate oxygen reserves in patients undergoing awake craniotomy.

Keywords: Airway obstruction; Craniotomy; Hypoxia; Respiratory insufficiency; Sleep apnea, obstructive.
Awake craniotomy has become a feasible treatment option for patients with brain tumors residing within or close to regions presumed to have language or sensorimotor functions [1]. Different anesthetic techniques, including conscious sedation with monitored anesthesia care (MAC) and the asleep-awake-asleep technique, have been applied for awake craniotomy [2]. However, in all these techniques, respiratory depression, including desaturation and hypercapnia during surgery, has been reported as an important complication [3].
Various techniques have been introduced to reduce the risk of respiratory insufficiency. The use of a high-flow nasal cannula (HFNC) can improve oxygenation compared to conventional oxygen devices by reducing the anatomical dead space, producing positive airway pressure, and facilitating the clearance of carbon dioxide in patients with spontaneous respiration [4]. Moreover, HFNC with a humidifier and heated circuit can deliver a conditioned gas mixture through a nasal cannula at up to $60 \mathrm{~L} / \mathrm{min}$ with a fraction of inspired oxygen $\left(\mathrm{FiO}_{2}\right)$ ranging from 0.21 to 1 for better pa-

This is an Open Access article distributed under the terms of the Creative Commons Attribution Non-Commercial License (http://creativecommons.org/licenses/by-nc/4.0) which permits unrestricted non-commercial use, distribution, and reproduction in any medium, provided the original work is properly cited.

Copyright (C) the Korean Society of Anesthesiologists, 2021 
tient comfort [3]. On the other hand, the oxygen reserve in$\operatorname{dex}(\mathrm{ORi})$, a tool for measuring the oxygen reserve, is reportedly useful for the early detection of hypoxia $[5,6]$. The measurement of partial pressure of oxygen $\left(\mathrm{PaO}_{2}\right)$ by atrial blood gas analysis is intermittent and requires invasive techniques. Pulse oximetry saturation $\left(\mathrm{SpO}_{2}\right)$ can detect hypoxia, but responds slowly and may not significantly decrease until the $\mathrm{PaO}_{2}$ is below $80 \mathrm{mmHg}$ [7]. ORi is a unitless index from zero to 1 , which correlates with $\mathrm{PaO}_{2}$. A sharp decrease in ORi or a drop to zero means that the oxygen reserve is low, and hypoxia is expected soon. This continuous and noninvasive technique enables early warning to prevent desaturation. We report two cases of patients who underwent moderate to conscious sedation for awake craniotomy. In two cases, a combination of HFNC and ORi was used to prevent respiratory insufficiency. Our Institutional Review Board (no. SMC 2020-11-109) approved this study and waived the requirement for written informed consent.

\section{CASE REPORT}

\section{Case 1}

The patient was a 58-year-old male with glioblastoma located near Broca's area. Brain functional magnetic resonance imaging showed that the motor and sensory cortices were located anterior to the mass. To preserve language and motor function, an awake craniotomy was scheduled [1]. Preoperative physical examination with an anesthetic evaluation, including the airway, was performed. The patient was taking medication for dyslipidemia, and his cardiopulmonary function was normal. His mallampati score was 2 , and there were no abnormalities in the anatomy of the airway. The body mass index (BMI) was $26.5 \mathrm{~kg} / \mathrm{m}^{2}$, and the patient reported that he snores heavily when sleeping. To assess obstructive sleep apnea (OSA), the STOP-BANG (acronym for Snoring, Tiredness, Observed apnea, high blood Pressure, Body mass index, Age, Neck circumference, and Gender) questionnaire was used, based on which he was classified as having a high risk of OSA. We applied the HFNC (AIRVO 2 system, Fisher \& Paykel, New Zealand) to improve oxygenation during surgery [4]. $\mathrm{EtCO}_{2}$ was monitored using a commercial sample line provided with the AIRVO 2 system. In addition, we monitored ORi to measure the oxygen reserve and the effectiveness of HFNC.

We used standard monitors (electrocardiogram, noninvasive blood pressure, end-tidal carbon dioxide, and pulse ox- imeter) with a bispectral index (BIS VISTA, Aspect Medical Systems, USA) sensor and administered $4 \mathrm{mg}$ of ondansetron, $0.2 \mathrm{mg}$ of glycopyrrolate, and $1 \mathrm{mg}$ of midazolam as premedication. The scalp nerve block (a perineural injection of $0.75 \%$ ropivacaine [ $26 \mathrm{ml}$ ] mixed with 1:200,000 epinephrine) was performed by an experienced anesthesiologist to block the supraorbital, supratrochlear, auriculotemporal, zygomaticotemporal, lesser occipital, and greater occipital nerves [8]. After initiating MAC with propofol and remifentanil, radial arterial cannulation was performed for invasive arterial monitoring, followed by insertion of a peripheral intravenous cannula and Foley catheter. For effect-site target-controlled infusion (TCI) for MAC, a commercial TCI pump (Orchestra Base Primea, Fresinus Vial, France) was used, and the pharmacokinetic set used to calculate the target effect site concentration (Ce) was the Minto model for remifentanil and Schneider model for propofol [2]. Usually, the target BIS is 60-70 during sedation for craniotomy [4], but in this case, we targeted the BIS above 70 to reduce the potential risk of airway obstruction following deep sedation. We applied both HFNC and ORi at the beginning of sedation and adjusted the flow and $\mathrm{FiO}_{2}$ of $\mathrm{HFNC}$ when ORi dropped to nearly zero, which is an early indicator of hypoxia.

Fig. 1 shows the values of $\mathrm{ORi}, \mathrm{FiO}_{2}$ of $\mathrm{HFNC}$, and $\mathrm{SpO}_{2}$ during surgery. At the beginning of sedation, HFNC was applied at $15 \mathrm{~L} / \mathrm{min}$ and $\mathrm{FiO}_{2}$ at 0.4 . At this time, the $\mathrm{PaO}_{2}$ and $\mathrm{SpO}_{2}$ were $118.3 \mathrm{mmHg}$ and $100 \%$, respectively. When we increased the target $\mathrm{Ce}$ of remifentanil before the expected stimulation, such as head fixation and incision, a sudden decrease in ORi to zero occurred, but ORi was recovered by increasing $\mathrm{FiO}_{2}$. During the speech test, ORi dropped to zero. Although oxygen saturation was maintained at $100 \%$, ORi remained at zero even when the flow of HFNC increased from $15 \mathrm{~L} / \mathrm{min}$ to $30 \mathrm{~L} / \mathrm{min}$. As he was almost awake, the possibility of airway obstruction was low; therefore, we checked the HFNC machine and found that the nasal cannula was pulled out while the patient was speaking. When the nasal cannula was applied to the patient again, the ORi recovered above 0.2. When ORi was zero, $\mathrm{SpO}_{2}$ was $100 \%$, but dropped to $95 \%$ transiently after ORi recovered. During the speech test, the ORi repeatedly dropped to zero, confirming that the nasal cannula was removed from the patient. After the neurologic examination, ORi was maintained above 0.2 with $\mathrm{FiO}_{2}$ at 0.6 and a flow rate of $30 \mathrm{~L} / \mathrm{min}$ with HFNC until the end of the surgery (Table 1). The estimated blood loss was $300 \mathrm{ml}$, heart rate was approximately 70 beats per minute, and mean arterial blood pressure was main- 


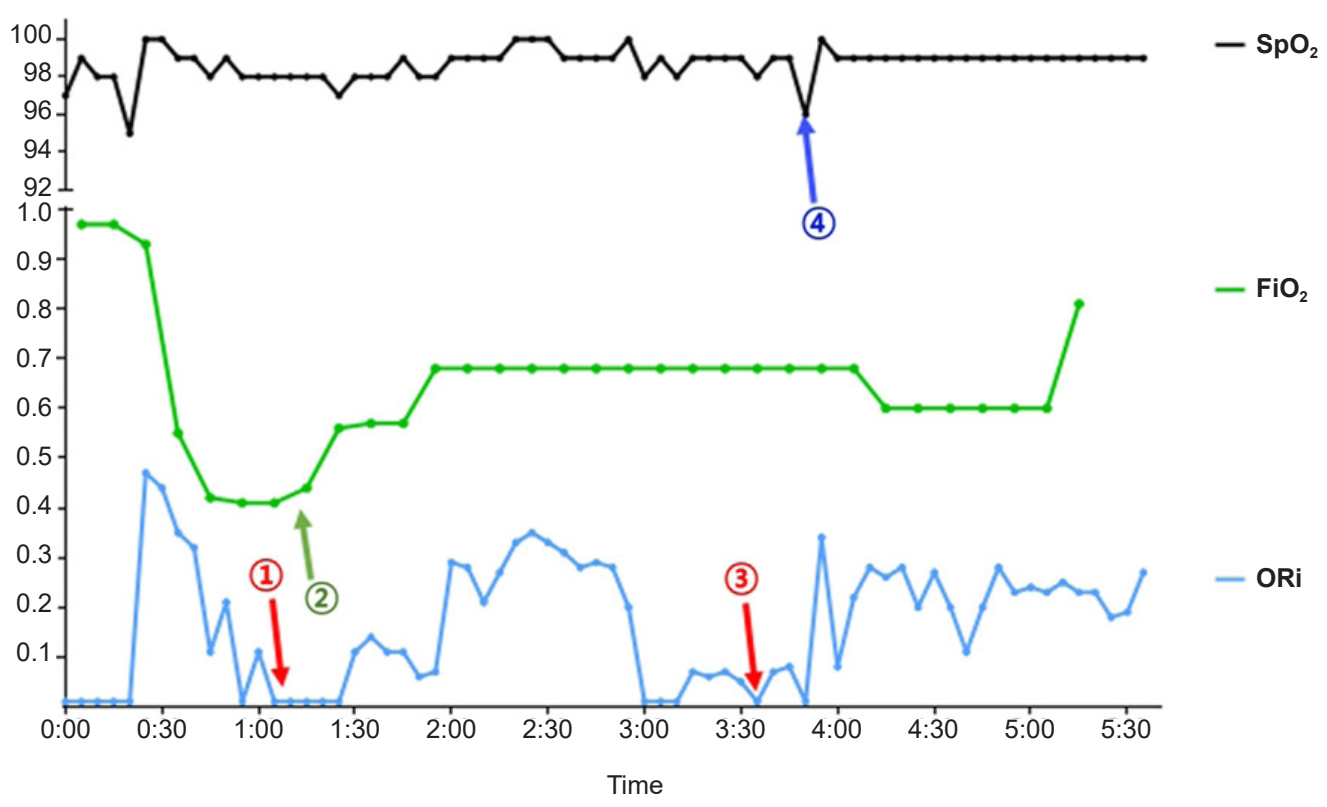

Fig. 1. Intraoperative $\mathrm{ORi}, \mathrm{SpO}_{2}$, and $\mathrm{FiO}_{2}$ of $\mathrm{HFNC}$ in Case 1. ORi: oxygen reserve index, $\mathrm{SpO}_{2}$ : pulse oximetry saturation, $\mathrm{FiO} \mathrm{O}_{2}$ : fraction of inspired oxygen, HFNC: high flow nasal cannula. This figure reveals the change of ORi and $\mathrm{SpO}_{2}$ over time and $\mathrm{FiO}_{2}$ we adjusted in Case 1. We maintained ORi above 0.2 by adjusting the $\mathrm{FiO}_{2}$ and flow rate of HFNC. The time and arrow in parentheses is the same as the time and arrow in Table 1. (1) ORi suddenly decreased to zero (time from 1:10 to 1:30). (2) ORi recovered by increasing $\mathrm{FiO}_{2}$ to 0.56 . (3) $\mathrm{During}$ the speech test (time from 3:00 to 3:50), the ORi suddenly dropped to zero. (4) $\mathrm{SpO}_{2}$ reacted later than ORi, it decreased to $95 \%$.

tained above $70 \mathrm{mmHg}$ during the surgery. The patient underwent successful awake craniotomy and tumor resection without any loss of neurological function or perioperative adverse events.

\section{Case 2}

The patient was a 33-year-old male with a low-grade glioma located in the left basal ganglia near the inferomedial aspect of Broca's area. He had smoked for 14 years, and his cardiopulmonary function was within normal limits. His BMI was $25.3 \mathrm{~kg} / \mathrm{m}^{2}$, and physical examination revealed a mallampati score of 2 and no evidence of airway abnormality or signs of OSA with normal $\mathrm{PaO}_{2}$ before surgery. Anesthesia was performed in the same order as described in the previous case. The scalp nerve was blocked using $30 \mathrm{ml}$ of $0.75 \%$ ropivacaine with 1:200,000 epinephrine. We applied $\mathrm{HFNC}$ at $30 \mathrm{~L} / \mathrm{min}$ and $\mathrm{FiO}_{2}$ at 0.5 , with ORi monitoring. After sedation, the $\mathrm{PaO}_{2}$ was $387.3 \mathrm{mmHg}$ under HFNC. The patient was sedated with a target BIS of 60-70. The ORi value was recorded throughout the surgery.

After the initiation of sedation, the ORi suddenly decreased to zero; therefore, we increased the $\mathrm{FiO}_{2}$ to 0.77 . Five minutes later, the ORi was restored to 0.29 ; accordingly, the
$\mathrm{FiO}_{2}$ was changed to 0.5 . During the surgery, the ORi suddenly decreased again from 0.45 to 0.2 , for which the $\mathrm{FiO}_{2}$ was increased briefly to 0.77 before reducing it back to 0.5 after recovery of ORi. Oxygen saturation remained at $100 \%$, while ORi changed from 0 to 0.85 throughout the surgery. During surgery, sedation and awake procedures were performed. While the ORi tended to increase temporarily when the patient woke up, there was no significant relationship between changes in ORi and patient consciousness.

The patient underwent extensive sensory and motor testing as well as neurocognitive testing, including naming, reading, counting, and verbal fluency. The total estimated blood loss was $300 \mathrm{ml}$, heart rate was 90 to 100 beats per minute, and mean arterial blood pressure was above 80 $\mathrm{mmHg}$, which was similar to that before surgery. TCI sedative agents and HFNC regimen were recorded (Table 2). The patient underwent successful awake craniotomy and tumor resection without any loss of neurological function or perioperative adverse events.

\section{DISCUSSION}

In these two cases, the patients underwent MAC during awake craniotomy. They were awake during the neurologi- 
Table 1. TCI Sedative Agents and HFNC Regimen in Relation to Intraoperative Events in Case 1

\begin{tabular}{|c|c|c|c|c|c|c|c|c|c|}
\hline \multirow[b]{2}{*}{ Event (time) } & \multicolumn{2}{|c|}{ HFNC } & \multirow[b]{2}{*}{ BIS } & \multirow{2}{*}{$\begin{array}{c}\mathrm{TCl}, \\
\text { remifentanil } \\
(\mathrm{Ce}, \mu g / \mathrm{kg} / \\
\mathrm{min})\end{array}$} & \multirow{2}{*}{$\begin{array}{c}\mathrm{TCl}, \\
2 \% \text { propofol } \\
\text { (Ce, } \mu \mathrm{g} / \mathrm{kg} / \\
\text { min) }\end{array}$} & \multirow[b]{2}{*}{$\mathrm{SpO}_{2}(\%)$} & \multirow[b]{2}{*}{$\begin{array}{c}\mathrm{PaO}_{2} \\
(\mathrm{mmHg})\end{array}$} & \multirow[b]{2}{*}{$\begin{array}{c}\mathrm{PaCO}_{2} \\
(\mathrm{mmHg})\end{array}$} & \multirow[b]{2}{*}{ Comments } \\
\hline & $\mathrm{FiO}_{2}$ & $\begin{array}{c}\text { Flow } \\
(\mathrm{L} / \mathrm{min})\end{array}$ & & & & & & & \\
\hline Start of sedation (0:50) & 0.4 & 15 & 83 & 0.8 & 1 & 100 & 118.3 & 51 & \\
\hline Head pin fixation $(1: 10)$ & 0.4 & 15 & 84 & 1.1 & 1.2 & 98 & & & $\begin{array}{l}\text { Increased the anesthetics } \\
\text { in advance due to } \\
\text { expected stimulation }\end{array}$ \\
\hline $\begin{array}{l}\text { ORi decreased to } 0 \\
(1: 10 \text { to } 1: 30) \downarrow 1\end{array}$ & 0.56 & 15 & 72 & 0.8 & 0.9 & $98 \rightarrow 97$ & & & $\begin{array}{l}\text { ORi recovered by raising } \\
\mathrm{FiO}_{2} \text { of } \mathrm{HFNC} \uparrow(2)\end{array}$ \\
\hline ORi fell close to $0(1: 50)$ & 0.68 & 15 & 74 & 0.5 & 0.8 & $98 \rightarrow 99$ & 143 & 58 & $\begin{array}{l}\text { Start of surgery, ORi } \\
\text { recovered by raising } \mathrm{FiO}_{2} \\
\text { of } \mathrm{HFNC}\end{array}$ \\
\hline \multirow{2}{*}{$\begin{array}{l}\text { ORi dropped to } 0 \\
\text { (3:00 to } 3: 50) \downarrow(3)\end{array}$} & \multirow[t]{2}{*}{0.68} & \multirow[t]{2}{*}{30} & \multirow[t]{2}{*}{87} & \multirow[t]{2}{*}{0.4} & \multirow[t]{2}{*}{0} & \multirow[t]{2}{*}{$100 \rightarrow 95(4) \rightarrow 99$} & & & Speech test \\
\hline & & & & & & & & & $\begin{array}{l}\text { Raised flow rate of HFNC, } \\
\text { detect disloged nasal } \\
\text { cannula \& re-apply, } \\
\text { desaturation developed } \\
\uparrow \text { (4) and recovered }\end{array}$ \\
\hline End of testing $(4: 10)$ & 0.6 & 30 & 94 & 0.4 & 0.3 & 98 & 223 & 40 & $\begin{array}{l}\text { Decreased } \mathrm{FiO}_{2} \text { of } \mathrm{HFNC} \\
\text { because } \mathrm{PaO}_{2} \text { was } 223 \\
\mathrm{mmHg}\end{array}$ \\
\hline
\end{tabular}

BIS: bispectral index, Ce: effect site concentration, $\mathrm{FiO}_{2}$ : fraction of inspired oxygen, HFNC: high flow nasal cannula, TCl: target-controlled infusion, ORi: oxygen reserve index, $\mathrm{PaO}_{2}$ : partial pressure of oxygen, $\mathrm{SpO}_{2}$ : oximetry saturation, $\mathrm{PaCO}_{2}$ : partial pressure of alveolar carbon dioxide. When we recorded BIS, it was the lowest value for that time period. The time and arrow in parentheses is the same as the time and arrow in Fig. 1. We started TCl of sedative agents (time 0:50), with applying $\mathrm{HFNC}$ as $15 \mathrm{~L} / \mathrm{min}$ and $\mathrm{FiO}_{2}$ as 0.4 . When pinned to the head, after increasing the dose of remifentanil, ORi suddenly decreased to zero (time from 1:10 to 1:30, marked by (1) in the Fig. 1). It recovered by increasing $\mathrm{FiO}_{2}$ to 0.56 (marked by (2) in the Fig. 1). When the surgery started (time 1:50), ORi again fell close to zero and we raised $\mathrm{FiO} \mathrm{O}_{2}$ to 0.68 after which ORi recovered. During the speech test (time from 3:00 to 3:50), the ORi repeatedly dropped to zero (marked by (3) in the Fig. 1), each time confirming that the nasal cannula was removed from the patient. When the nasal cannula applied to the patient again, ORi recovered above 0.2. $\mathrm{SpO}_{2}$ reacted later than ORi (marked by (4) in the Fig. 1). After the neurologic exam, $\mathrm{PaO}_{2}$ in arterial blood gas analysis was $223 \mathrm{mmHg}$, we adjusted $\mathrm{FiO}_{2}$ as 0.6 and flow rate as $30 \mathrm{~L} / \mathrm{min}$ with $\mathrm{HFNC}$ until the end of the surgery.

Table 2. TCI Sedative Agents and HFNC Regimen in Relation to Intraoperative Events in Case 2

\begin{tabular}{|c|c|c|c|c|c|c|}
\hline \multirow{2}{*}{ Event } & \multicolumn{2}{|c|}{ HFNC } & \multirow{2}{*}{ BIS } & \multirow{2}{*}{$\begin{array}{l}\text { TCl, remifentanil } \\
(\mathrm{Ce}, \mu \mathrm{g} / \mathrm{kg} / \mathrm{min})\end{array}$} & \multirow{2}{*}{$\begin{array}{l}\mathrm{TCl}, 2 \% \text { propofol } \\
\text { (Ce, } \mu \mathrm{g} / \mathrm{kg} / \mathrm{min})\end{array}$} & \multirow{2}{*}{ Comment } \\
\hline & $\mathrm{FiO}_{2}$ & Flow (L/min) & & & & \\
\hline During induction & 0.5 & 30 & 75 & 1 & 1 & \\
\hline $\begin{array}{l}\text { Head pin fixation, } \\
\text { dura opening }\end{array}$ & 0.5 & 30 & 80 & 1.3 & 1.3 & $\begin{array}{l}\text { Increased the anesthetics in advance } \\
\text { due to expected stimulation at the be- } \\
\text { ginning of the surgery }\end{array}$ \\
\hline ORi decreased to 0 & 0.77 & 30 & 66 & 1.3 & 1.3 & Raised $\mathrm{FiO}_{2}$ of $\mathrm{HFNC}$ \\
\hline Neurologic exam & 0.5 & 30 & 73 & 0 & 0 & ORi has recovered, $\mathrm{FiO}_{2}$ is lowered again \\
\hline End of testing & 0.77 & 30 & 64 & 0.5 & 0.7 & $\begin{array}{l}\text { ORi decreased rapidly, raised } \mathrm{FiO}_{2} \text { of } \\
\text { HFNC }\end{array}$ \\
\hline Wound closure & 0.5 & 30 & 55 & 1.1 & 1.2 & ORi has recovered, $\mathrm{FiO}_{2}$ is lowered again \\
\hline
\end{tabular}

BIS: bispectral index, Ce: effect site concentration, $\mathrm{FiO}_{2}$ : fraction of inspired oxygen, HFNC: high flow nasal cannula, TCl: target-controlled infusion, ORi: oxygen reserve index. When we recorded BIS, it was the lowest value for that time period. The TCI model used the Schneider model.

cal examination, but remained sedated during the rest of the procedure. We used propofol and remifentanil as sedatives [2], which may induce respiratory insufficiency in a dose-dependent manner. In particular, in patients with OSA, even a small increase in the sedative dose may cause unexpected respiratory insufficiency; therefore, the dose of the sedative was adjusted under close monitoring of BIS. Airway obstruction due to respiratory insufficiency can cause intracranial hypertension [4]; therefore prompt management is required. However, securing the airway with laryngeal mask airway insertion or endotracheal intubation is challenging in patients undergoing awake craniotomy because of unusual positions 
and head fixation, which may delay prompt airway intervention and lead to serious consequences during surgery.

To prevent respiratory insufficiency, we attempted to improve oxygenation by applying HFNC. MAC with HFNC is a reasonable option for patients undergoing awake craniotomy, especially for those with OSA [4]. A high flow of oxygen is supplied to generate resistance to expiratory flow, resulting in a continuous positive airway pressure effect. According to the other study, when HFNC was applied at $35 \mathrm{~L} / \mathrm{min}$, positive pressures produced $2.7 \mathrm{cmH}_{2} \mathrm{O}$ with the mouth open and $1.2 \mathrm{cmH}_{2} \mathrm{O}$ with the mouth closed, and the difference was more pronounced when the BMI was higher [9]. In addition, carbon dioxide is easily released and the dead space is decreased, which is effective in resolving dyspnea [10]. In addition, humidified gas improves mucociliary function, helps secretion clearance, and reduces atelectasis [4]. These advantages of HFNC are particularly useful in patients with OSA undergoing awake craniotomy.

ORi is a noninvasive and continuous supplemental tool that can provide early warning to clinicians regarding changes in a patient's oxygen reserve. It is a unitless index between 0 and 1 , where 0 indicates a decrease in $\mathrm{PaO}_{2}$ and impending hypoxia $[5,11]$. In the study of ORi and $\mathrm{PaO}_{2}$, they were significantly correlated; moreover, a decrease in ORi to approximately 0.24 may provide an advanced indication of decreasing $\mathrm{PaO}_{2}$ [11]. The ORi was reported to detect an impending desaturation at a median duration of $31.5 \mathrm{~s}$ before any noticeable changes in $\mathrm{SpO}_{2}$ occurs during surgery in children [12]. In the first case, ORi decreased several times but was recovered by slightly increasing the $\mathrm{FiO}_{2}$ of the HFNC. During neurological examination, ORi detected hypoxia faster than $\mathrm{SpO}_{2}$. The ORi dropped to zero while the HFNC was pulled out, but $\mathrm{SpO}_{2}$ remained at $100 \%$. After reapplying HFNC, ORi was maintained above 0.2 , but $\mathrm{SpO}_{2}$ dropped to $95 \%$ only and recovered soon, indicating that the change in ORi was faster than that of $\mathrm{SpO}_{2}$. At that time, we could not measure the exact value of $\mathrm{PaO}_{2}$ by arterial blood gas analysis, but if we did not measure the ORi, it would have been late to find out that HFNC was pulled out and respiratory insufficiency would have occurred. Although the patient was awake, remifentanil was continuously infused during the neurological examination; therefore, he could easily experience hypoxia. ORi allows real-time surveillance of the oxygenation status and may enable proactive interventions to avoid hypoxia. In the second case, we adjusted the $\mathrm{FiO}_{2}$ of the HFNC when ORi decreased; thus, $\mathrm{SpO}_{2}$ remained at $100 \%$. The flow rate of HFNC was maintained at $30 \mathrm{~L} / \mathrm{min}$ from the beginning, but as in the first case, the oxygen reserve could be properly maintained by adjusting the flow rate of the HFNC. HFNC helps to prevent hypoxia while preventing airway obstruction by controlling $\mathrm{FiO}_{2}$ to values from 0.2 to 1 and providing a positive end-expiratory pressure effect. Although it is still controversial, since hyperoxia might have a negative effect on craniotomy [13], it is recommended to maintain normoxia during and after craniotomy [14]. Hyperoxia could occur due to HFNC; thus, decreasing the $\mathrm{FiO}_{2}$ when the ORi approaches 1 might help to maintain normoxia.

In conclusion, the combination of HFNC and ORi monitoring could provide adequate oxygen reserve in patients while effectively preventing a decrease in oxygen saturation during awake craniotomy.

\section{CONFLICTS OF INTEREST}

No potential conflict of interest relevant to this article was reported.

\section{DATA AVAILABILITY STATEMENT}

Data sharing not applicable to this article as no datasets were generated or analyzed during the current study.

\section{AUTHOR CONTRIBUTIONS}

Conceptualization: Ji-Hye Kwon, Jeonjin Lee. Data curation: Joonhee Gook, Jung Won Choi, Keoungah Kim. Formal analysis: Joonhee Gook, Ji-Hye Kwon, Jung Won Choi. Methodology: Jeonjin Lee. Project administration: Jeonjin Lee. Visualization: Joonhee Gook. Writing - original draft: Joonhee Gook. Writing - review \& editing: Ji-Hye Kwon, Keoungah Kim. Investigation: Joonhee Gook, Ji-Hye Kwon. Resources: Ik Soo Chung. Software: Ji-Hye Kwon. Supervision: Jeonjin Lee, Ik Soo Chung. Validation: Ik Soo Chung.

\section{ORCID}

Joonhee Gook, https://orcid.org/0000-0002-1812-6694

Ji-Hye Kwon, https://orcid.org/0000-0002-8899-0699

Jung Won Choi, https://orcid.org/0000-0002-7425-6784

Keoungah Kim, https://orcid.org/0000-0002-4924-1046

Ik Soo Chung, https://orcid.org/0000-0002-0082-5083

Jeonjin Lee, https://orcid.org/0000-0003-4728-1762 


\section{REFERENCES}

1. Hervey-Jumper SL, Li J, Lau D, Molinaro AM, Perry DW, Meng L, et al. Awake craniotomy to maximize glioma resection: methods and technical nuances over a 27 -year period. J Neurosurg 2015; 123: 325-39.

2. Kim SH, Choi SH. Anesthetic considerations for awake craniotomy. Anesth Pain Med (Seoul) 2020; 15: 269-74.

3. Smith SC, Burbridge M, Jaffe R. High flow nasal cannula, a novel approach to airway management in awake craniotomies. J Neurosurg Anesthesiol 2018; 30: 382.

4. Wong JWM, Kong AHS, Lam SY, Woo PYM. High-flow nasal oxygen in patient with obstructive sleep apnea undergoing awake craniotomy: a case report. A A Case Rep 2017; 9: 353-6.

5. Scheeren TWL, Belda FJ, Perel A. The oxygen reserve index (ORI): a new tool to monitor oxygen therapy. J Clin Monit Comput 2018; 32: 379-89.

6. Fleming NW, Singh A, Lee L, Applegate RL 2nd. Oxygen reserve index: utility as an early warning for desaturation in high-risk surgical patients. Anesth Analg 2021; 132: 770-6.

7. Davis DP, Hwang JQ, Dunford JV. Rate of decline in oxygen saturation at various pulse oximetry values with prehospital rapid sequence intubation. Prehosp Emerg Care 2008; 12: 46-51.
8. Amato AC, Pescatori M. Effect of perioperative blood transfusions on recurrence of colorectal cancer: meta-analysis stratified on risk factors. Dis Colon Rectum 1998; 41: 570-85.

9. Parke RL, Eccleston ML, McGuinness SP. The effects of flow on airway pressure during nasal high-flow oxygen therapy. Respir Care 2011; 56: 1151-5.

10. Jeong JH, Kim DH, Kim SC, Kang C, Lee SH, Kang TS, et al. Changes in arterial blood gases after use of high-flow nasal cannula therapy in the ED. Am J Emerg Med 2015; 33: 1344-9.

11. Applegate RL 2nd, Dorotta IL, Wells B, Juma D, Applegate PM. The relationship between oxygen reserve index and arterial partial pressure of oxygen during surgery. Anesth Analg 2016; 123: 626-33.

12. Szmuk P, Steiner JW, Olomu PN, Ploski RP, Sessler DI, Ezri T. Oxygen reserve index: a novel noninvasive measure of oxygen reserve--a pilot study. Anesthesiology 2016; 124: 779-84.

13. Schaffranietz L, Vetter B, Rudolph C, König F. [Hyperoxia-induced liberation of big-endothelin into jugular venous blood of electric neurosurgical patients]. Anaesthesiol Reanim 2001; 26: 123-32. German.

14. Lumb AB, Walton LJ. Perioperative oxygen toxicity. Anesthesiol Clin 2012; 30: 591-605. 